\title{
Med Moth: A Storytelling Platform for Improving Wellness in Medical Education
}

Michelle Silver, ${ }^{1}$ Sarah Ohnigian, ${ }^{2}$ Hugh Silk, ${ }^{3}$ Michael Ennis, ${ }^{4}$ Judith Savageau. ${ }^{5}$

\begin{abstract}
Background: Burnout is a major issue amongst medical students and professionals that demands a solution. Mindfulness has been shown to decrease burnout. Storytelling, as a form of mindfulness, leads to reflection. Few publications have studied the effect of storytelling on student and clinician wellness. To address wellness within their medical community and utilize the underexplored method of narrative medicine as a curricular enhancement, the authors designed and implemented a novel storytelling platform, Med Moth, at the University of Massachusetts Medical School (UMMS) and associated hospital (UMass Memorial Medical Center). Methods: Members of the community were invited to storytelling events to listen to and share stories about formative medical experiences. Four events were held between 2017 and 2018. After each event, participants received a survey inquiring how attendance benefitted them personally and professionally. Results: Clinicians, students, and faculty comprised the 104 first-time attendees surveyed. Med Moth produced a strong perceived benefit to surrogate measures including emotional exhaustion and depersonalization, defining characteristics of burnout, and professional development. Among these three measures, $66 \%$ of participants rated 4-5 (out of 5 ). Nearly all attendees ( $96 \%$ ) rated 4-5 for the overall experience. Lastly, medical students reported a higher benefit regarding professional development than clinicians $(p=0.002)$. Conclusions: This pilot study of a novel storytelling platform demonstrates positive personal and professional development outcomes, both during and after medical school training. Medical schools, residency programs, and medical institutions should strongly consider the implementation of such a wellness platform to build resiliency and to mitigate burnout through reflection.
\end{abstract}

Key Words: Professional Burnout; Medical Education; Mindfulness; Medical students; Curriculum; Health promotion (Source: MeSH-NLM).

\section{Introduction}

Clinicians and medical students face high rates of stress and burnout..$^{1-3}$ These symptoms adversely affect mental health and manifest as depression, anxiety, and fatigue. 4 In a recent study of 4,000 US medical students, $49 \%$ reported signs of burnout. ${ }^{7}$ Depression is also more common among medical students and residents than the general population. ${ }^{4}$ These issues are not only deleterious to the health of medical providers, but also to their patients. ${ }^{4}$

Burnout is unequivocally present among medical students and professionals and requires a solution. Mindfulness can decrease burnout and improve depression and anxiety. It can also cultivate compassion, empathy, and personal and professional identity development. ${ }^{6-10}$ Mindfulness training teaches participants to approach lived experiences in an introspective way. Reflective practice is one application of mindfulness. It leads to understanding one's beliefs and values in the context of one's colleagues and patients. Medical students who engage in reflection display more mature thinking, certainty with professional choices, and report a positive learning experience. ${ }^{11}$

Storytelling is an excellent means of reflective practice, allowing one to be present, compassionate, and deepen community connections. A recent article by Perri Klass entitled "Morality Tales" discusses the trend toward medical humanism with students and residents increasingly "tak[ing] time to consider and describe the complex aspects of medical stories that get left out of the formalisms of the medical record." 12 Outside of medicine, storytelling is well-established. Novelist George Green embraced its impactful nature when creating The Moth, an internationally acclaimed storytelling organization. ${ }^{13}$

There are only a few studies that have directly assessed the effect of storytelling on student and clinician burnout. One study showed that medical students who participated in storytelling sessions with peers demonstrated an increase in the empathy score. ${ }^{14}$ Other published accounts of storytelling's effect on clinician burnout are mainly personal experiences of physicians who cite benefits such as improved patient relationships and collegial communication. ${ }^{15}$

To address burnout within our medical community, we created a novel storytelling opportunity at UMass Medical School (UMMS) and associated hospital (UMass Memorial Medical Center). Inspired by The Moth, Med Moth was created to provide a platform for members to listen, share, and reflect. Med Moth was created to positively impact personal wellness and professional development through sharing clinical perspectives and experiences. We aimed to identify individual characteristics that correlate with a higher impact of this platform.

\footnotetext{
MD, Hospital of the University of Pennsylvania Department of Internal Medicine, Philadelphia, PA, United States*

MD, Beth Israel Deaconess Medical Center Department of Internal Medicine, Boston, MA, United States*

3 MD, MPH, University of Massachusetts Department of Family Medicine and Community Health, Worcester, MA, United States

4 MD, University of Massachusetts Department of Family Medicine and Community Health, Worcester, MA, United States

$5 \mathrm{MPH}$, University of Massachusetts Department of Family Medicine and Community Health, Worcester, MA, United States
}

${ }^{*}$ Research was conducted at the University of Massachusetts Medical School prior to the graduation of first and second authors, who are now listed with their current institutional affiliation

About the Author: Michelle Silver is a second-year Internal Medicine resident at the Hospital of the University of Pennsylvania (Philadelphia, PA) where she started training after receiving her medical degree from the University of Massachusetts Medical School (Worcester, MA). Her career interests include primary care, medical education, and exploring the role of narrative medicine for medical trainees and professionals.

Correspondence:

Michelle Silver

Address: 3400 Spruce Street Philadelphia, PA 19104, USA

Email: michelle.silver8@gmail.com
Editor: Francisco J. Bonilla-Escobar Student Editors: Diego Carrion Alvarez e Manas Pustake Copyeditor: Sohaib Haseeb Proofreader: Adam Urback Layout Editor: Anna-Maria Chantaliyska
Submission: Jun 4, 2021 Revisions required: Jul 1, 2021 Received in revised form: Jul 13,2021 Acceptance: Sep 25, 2027 Publication: Dec 14, 2021 Process: Peer-reviewed 


\section{Methods}

Participants (attendees and speakers) were members of the UMMS community, including medical students, nursing students, clinicians, faculty, and administrators. Participants were recruited via Facebook, student events, web-based school news outlets, posters, and listservs.

We held four, 1.5-hour events (March 2017 to October 2018), each with 8 to 10 speakers. Stories were prescreened for protected patient information. Speakers shared poetry or prose with topics ranging from clinical mistakes, "why medicine", to comedic misunderstandings with patients. Refreshments were provided.

Using web-based data collection (Google Forms, Google LLC, Mountainview, CA), we emailed the survey three days after an event as a group message to all recipients who signed-in to the event. Participants were able to see all recipients of the email. Regarding the survey, multiple choice and free text questions characterized attendees by demographics and traits. This included affinity toward storytelling and an hourly breakdown of work, study, exercise, and other commitments. Likert-scaled questions, ranging from 1 (a little) to 5 (a lot), assessed the degree of positive effect of attending Med Moth on two domains of interest: personal wellness and professional benefit. Personal wellness was divided into emotional exhaustion and depersonalization (based on the Maslach Burnout inventory), and professional benefit assessed how events would influence clinical practice. ${ }^{3}$ Where appropriate, we combined categories of 'often' and

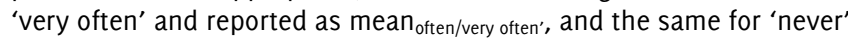
and 'sometimes' response options. The study was approved by the UMMS Institutional Review Board.

Using SPSS statistical software (SPSS v.23, IBM Corporation, 2015), survey questions on emotional exhaustion, depersonalization, and professional benefit were analyzed using chi-square tests, student ttests, correlations, and non-parametric equivalents for ordinal data. We used cumulative scores across all questions within a category (e.g., the two 5-point questions for emotional exhaustion yielded a maximum score of 10 ). We reported average scores per question to demonstrate trends.

We assessed relationships influencing the impact of Med Moth, including the level of training and participant characteristics. For each question, analyses were conducted across all three domains. For select analyses, original Likert scale responses were dichotomized for bivariate analyses. We used survey responses from first-time attendees only and excluded subsequent responses in the current analysis. We combined responses from residents and mid-level practitioners (e.g. nurse practitioners) with attending physicians to compare medical students to clinical practitioners.

\section{Results}

Med Moth experienced a growing number of attendees (41 participants in March 2017; 85 in October 2018): 236 total attendees, including 175 first-time attendees. There were 151 survey responses (64\% response rate). Analyses representing 104 surveys from first-time attendees showed a larger proportion of females, medical students, primary care, and senior clinicians (Table 1).

Nearly all first-time attendees ( $96 \%$ ) endorsed a high overall experience rating of 4-5 out of 5 . Perceived benefits in emotional exhaustion, depersonalization, and professional development were strong; twothirds $(66 \%)$ of participants reported high ratings of 4-5 out of 5 . Most (92\%) reported they would "definitely" attend another event (Figure 1). Medical students reported a significantly higher benefit for professional development compared to clinicians ( $p=0.002$; Table 2). Across all other measures, there were equally positive responses between groups.
Table 1. Demographic Characteristics of 104 First-Time Participants who Attended a Med Moth Storytelling Event at the University of Massachusetts Medical School, 2017-2018.

\begin{tabular}{|c|c|c|c|}
\hline Variable & $\begin{array}{l}\text { Clinical } \\
\text { Faculty* }^{*}\end{array}$ & $\begin{array}{l}\text { Medical } \\
\text { Students }\end{array}$ & $\begin{array}{l}\text { Non- } \\
\text { Clinical } \\
\text { Faculty }\end{array}$ \\
\hline n (\%) & $29(27.8)$ & $66(63.5)$ & $9(8.6)$ \\
\hline \multicolumn{4}{|l|}{ Age, $n(\%)$} \\
\hline$<30$ & $0(0)$ & $64(97)$ & $1(11.1)$ \\
\hline $30-49$ & $10(34.5)$ & $2(3)$ & $4(44.4)$ \\
\hline$\geq_{50}$ & $19(65.5)$ & $0(0)$ & $4(44.4)$ \\
\hline \multicolumn{4}{|l|}{ Gender, n(\%) } \\
\hline Female & $18(62)$ & $49(74.3)$ & $9(100)$ \\
\hline Male & $11(38)$ & $17(25.7)$ & $0(0)$ \\
\hline \multicolumn{4}{|l|}{ Years Practicing, n(\%) } \\
\hline $1-10$ & $6(20.7)$ & & \\
\hline $\begin{array}{l}11-20 \\
>20\end{array}$ & $\begin{array}{c}7(24.1) \\
16(55.2)\end{array}$ & N/A & $\mathrm{N} / \mathrm{A}$ \\
\hline \multicolumn{4}{|l|}{ Specialty, n(\%) } \\
\hline $\begin{array}{l}\text { Primary Care } \\
\text { (Internal } \\
\text { Pediatrics, } \\
\text { Medicine) }\end{array}$ & $13(44.8)$ & & \\
\hline Medicine Subspecialty & $2(6.7)$ & & \\
\hline Psychiatry & $2(6.7)$ & $\mathrm{N} / \mathrm{A}$ & $\mathrm{N} / \mathrm{A}$ \\
\hline Surgery & $1(3.4)$ & & \\
\hline Radiology & $1(3.4)$ & & \\
\hline Other/Blank & $10(34.5)$ & & \\
\hline
\end{tabular}

Legend: *Medical Doctor, Nurse Practitioner, Registered Nurse, Physician Assistant, Doctor of Philosophy.

Figure 1. Percentage of respondents $(n=104)$ who, on average, reported scores of 44 versus .4 for overall experience and for each of the three domains-emotional exhaustion, depersonalization, and professional development. A higher rating (.4) reflects a benefit to emotional exhaustion, depersonalization, and professional development, as well as a more positive overall experience. Reports were based on first-time attendance of a Med Moth Storytelling event at the University of Massachusetts Medical School, 2017-2018.

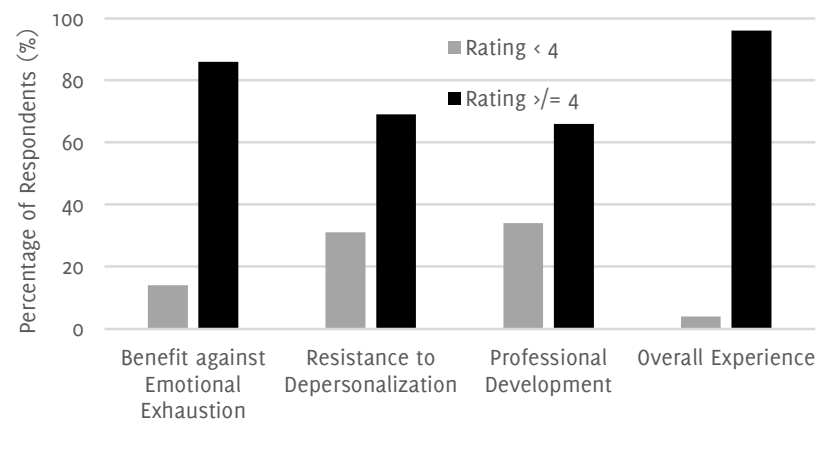

Participants who frequently sought storytelling outlets outside of Med Moth reported a greater personal benefit of attending the event. Specifically, those who often seek storytelling media as a listener or reader reported higher benefit against emotional exhaustion than those who rarely seek this out $\left(\right.$ mean $_{\text {often/very often }}=9.41 ;$ mean $_{\text {never } / \text { sometimes }}=8.63$; $\mathrm{t}=-2.86 ; \mathrm{p}=0.005$; Table 2 ). Those who sought storytelling as a speaker or writer reported higher benefit against depersonalization (mean $_{\text {often/very often }}=15.00 ;$ mean $_{\text {never/sometimes }}=12.55 ; \mathrm{t}=-9.59 ; \mathrm{p}<0.001 ;$ Table 2). No significant relationships were found with the remaining domains. 
Table 2. Comparison of Personal and Professional Benefits between various Subgroups of First-Time Participants who Attended a Med Moth Storytelling Event at the University of Massachusetts Medical School, 2017-2018.

\begin{tabular}{|c|c|c|c|c|c|c|c|c|c|}
\hline \multirow{3}{*}{ Personal Benefit } & \multicolumn{8}{|c|}{ Average Rating, mean (SD) } & \multirow[b]{3}{*}{$\mathrm{p}$-value } \\
\hline & & & & \multicolumn{3}{|c|}{ Story-Seekers } & \multicolumn{2}{|r|}{ Story-Tellers } & \\
\hline & $\begin{array}{l}\text { Medical } \\
\text { Students }\end{array}$ & Clinicians & $\mathrm{p}$ & $\begin{array}{l}\text { Frequent } \\
\text { often/ } \\
\text { very often }\end{array}$ & $\begin{array}{l}\text { Seldom } \\
\text { never/ } \\
\text { sometimes }\end{array}$ & $\mathrm{p}$ & $\begin{array}{l}\text { Frequent } \\
\text { often/ } \\
\text { very often }\end{array}$ & $\begin{array}{l}\text { Seldom } \\
\text { never/ } \\
\text { sometimes }\end{array}$ & \\
\hline $\begin{array}{l}\text { Benefit against } \\
\text { Emotional Exhaustion } \\
\text { *(max. points }=10)\end{array}$ & $\begin{array}{l}8.88(1.72) \\
{ }^{\star *} n=66\end{array}$ & $\begin{array}{c}8.90(1.47) \\
n=29\end{array}$ & 0.96 & $\begin{array}{c}9.41(0.94) \\
n=39\end{array}$ & $\begin{array}{c}8.63(1.84) \\
n=64\end{array}$ & 0.005 & $\begin{array}{c}9.00(2.24) \\
n=5\end{array}$ & $\begin{array}{c}8.92(1.58) \\
n=98\end{array}$ & 0.91 \\
\hline $\begin{array}{l}\text { Benefit against } \\
\text { Depersonalization } \\
(\text { max. points }=15)\end{array}$ & $\begin{array}{c}12.75(2.53) \\
n=65\end{array}$ & $\begin{array}{c}12.33(2.37) \\
n=27\end{array}$ & 0.46 & $\begin{array}{c}13.08(1.88) \\
n=37\end{array}$ & $\begin{array}{c}12.39(2.72) \\
n=59\end{array}$ & 0.15 & $\begin{array}{c}15.00(0.00) \\
n=4\end{array}$ & $\begin{array}{c}12.55(2.45) \\
n=92\end{array}$ & $<0.001$ \\
\hline $\begin{array}{l}\text { Professional Benefit } \\
(\max . \text { points }=10)\end{array}$ & $\begin{array}{c}8.21(1.84) \\
n=64\end{array}$ & $\begin{array}{c}6.60(2.35) \\
n=28\end{array}$ & 0.002 & $\begin{array}{c}7.68(2.04) \\
n=38\end{array}$ & $\begin{array}{c}7.83(2.15) \\
n=58\end{array}$ & 0.75 & $\begin{array}{c}8.80(1.79) \\
n=5\end{array}$ & $\begin{array}{c}7.71(2.10) \\
n=91\end{array}$ & 0.26 \\
\hline $\begin{array}{l}\text { Overall Satisfaction } \\
(\max . \text { points }=5)\end{array}$ & $\begin{array}{c}4.73(0.57) \\
n=66\end{array}$ & $\begin{array}{c}4.79(0.41) \\
n=29\end{array}$ & 0.58 & $\begin{array}{c}4.79(0.47) \\
n=39\end{array}$ & $\begin{array}{c}4.74(0.54) \\
n=65\end{array}$ & 0.59 & $\begin{array}{c}5(0.00) \\
n=5\end{array}$ & $\begin{array}{c}4.75(0.52) \\
n=99\end{array}$ & ${ }^{\star * *} 0.25$ \\
\hline
\end{tabular}

Legend: *indicates maximum score per category: responses were analyzed using the cumulative score across all questions, with a maximum of 5 points per question ** participants were only included in analyses when they answered all sub-questions within a domain, explaining varied $n$ per section

$\star * \star$ the non-parametric $\mathrm{p}$ value is being shown as this differed significantly from the traditional $t$-test because of the large difference in variances between the two groups

There were no significant correlations between hours of sleep or selfcare hours (exercise, relaxation, hobbies) and Med Moth ratings within any domain. However, there were moderately strong correlations between personal and professional ratings for all participants $(r=0.637$, $\mathrm{p}<0.001)$ and within stratified analyses among medical students $(r=0.680, p<0.001)$ and clinicians $(r=0.672, p<0.001)$.

In the open-ended text, participants described many benefits to attending Med Moth, including the promotion of optimism, resiliency, admiration, and inspiration. One student wrote: "Earlier in the day I was feeling tired and burnt out... I needed to remember why I wanted to be a doctor. This event was refreshing, enlightening, fun, and enjoyable. I left with a pep in my step and feeling energized and inspired. It reminded me...there are events like this where we can learn more about each other and take time to reflect and grow". Another student commented: "I often feel an underlying pressure to be perfect in medical school, and it is so powerful to hear the clinicians we aspire to be like also having faced situations that were far from perfect. These sessions have helped me ground my experience and realize that medicine will always be a process. Two faculty wrote: This was a new experience for me...one that was enriching and personally gratifying. Hearing the other stories, I was moved by the messaging with emotions ranging from laughter to tears; and: I've been at UMMS a little over 2 years, and this is the first time l've really felt connected to the community".

\section{Discussion}

Responses to Med Moth were overwhelmingly positive. Nearly all participants reported a high overall rating and indicated they would return. For emotional exhaustion, depersonalization, and professional development, greater than two-thirds of participants highly-rated the benefit of attending Med Moth. Many attendees commented that the program was inspiring and promoted both optimism and resiliency.

Regardless of role, there was a positive correlation between personal and professional ratings, which emphasizes benefit across all domains. Medical students reported higher benefits for professional development compared to clinicians. More importantly, clinicians and medical students reported a positive impact on emotional well-being and resistance against depersonalization - core features of burnout. Not surprisingly, individuals who seek storytelling outlets demonstrated greater benefits to emotional exhaustion and depersonalization. Overall, Med Moth appears to impact all participants on a humanistic and relational level. These findings echo a published systematic review showing that medical students who participate in storytelling sessions with peers demonstrate an increase in empathy scores. ${ }^{14}$ Studies on mindfulness further support these sentiments. One study showed that medical students who engage in reflection display more mature thinking, certainty with professional choices and a more positive learning experience with their clinical training. ${ }^{11}$ Other studies have demonstrated that mindfulness training improves measures of depression and anxiety, cultivates empathy, and inspires more thoughtful decision-making in medical students and physicians..$^{8,10} \mathrm{Med}$ Moth not only complements existing literature demonstrating the importance of reflection amongst medical professionals but also suggests an impactful and unique solution.

This study is timely; medical humanities are expanding and the need for wellness is now. , $^{7-11}$ Narrative medicine essays about wellness are increasing frequency and relevance in journals such as in The Journal of the American Medical Association (JAMA) and the New England Journal of Medicine. Health policy journals are following suit (e.g., Health Affairs section entitled "Narrative Matters"). The Accreditation Council for Graduate Medical Education (ACGME) now requires every accredited residency program to address well-being "and attend to resident and faculty member burnout [and] depression." Therefore, the application of a platform like Med Moth has significant potential in the larger realm of medical education. Barriers to medical storytelling will have to be addressed, including disregard of medical humanities as a valid form of education enrichment, lack of time, and denial of burnout in medicine.

With regards to limitations, our study may lack generalizability (conducted in one school and hospital). Our sample size of 104 limited our ability to conduct detailed subgroup analyses, and the $64 \%$ response rate may not reflect all attendees. Voluntary attendance and self-report may have yielded more positive reviews. Furthermore, bias could occur from the medical school being a small community and participants not wanting to be negative towards the student organizers of Med Moth. 
Our study serves as a pilot that begins to quantify the benefits of storytelling in medicine. We propose that a more objective and validated study of Med Moth and similar storytelling programs in medical communities be conducted. Ideally, data should be collected across multiple medical and health professional schools. Thereby, required storytelling events would increase sample size and generalizability in exploring potential discrepancies between regions and cultures. Future analyses should also assess change-over-time to identify the benefits of attending multiple events.

\section{References}

1. Dyrbye, L, Thomas M, Massie F, Power D, Eacker A, Harper W, et al. Burnout and suicidal ideation among US medical students. Ann Intern Med. 2008 Sep 2; 149(5):334-41.

2. Center C, Davis M, Detre T, Ford D, Hansbrough W, Hendin H, et al. Confronting depression and suicide in physicians: A consensus statement. JAMA. 2003 Jun 18; 289(23):3161-6.

3. Maslach C, Jackson S, Leiter M. Maslach burnout inventory: Third edition. In: Zalaquett CP, Wood RJ, (Eds.). Evaluating Stress: A Book of Resources. 1997; 191218. Scarecrow Education.

4. Shanafelt T, Dyrbye L. Oncologist burnout: causes, consequences, and responses. J. Clin Oncol. 2012 Apr 10;30(11):1235-41.

5. Goebert,D, Thompson D, Takeshita J, Beach C, Bryson P, Ephgrave K, et al. Depressive symptoms in medical students and residents: a multischool study. Acad Med. 2009 Feb;84(2):236-41.

6. Regehr C, Glancy D, Pitts A, LeBlanc VR. Interventions to reduce the consequences of stress in physicians: a review and meta-analysis. J Nerv Ment Dis. 2014 May;202(5):353-9.

7. Ruotsalainen JH, Verbeek JH, Mariné A, Serra C. Preventing occupational stress in healthcare workers. Cochrane Database Syst Rev. 2014 Nov 13;13(11): CD002892

8. Fortney I, Luchterhand C, Zakletskaia L, Zgierska A, Rakel D. Abbreviated mindfulness intervention for job satisfaction, quality of life, and compassion in primary care clinicians: a pilot study. Ann Fam Med. 2013 Sep-0ct;11(5):412-20.
Conclusively, storytelling events have great potential as curricular enhancement within medical education to help build resiliency and mitigate burnout. Medical institutions should strongly consider the implementation and evaluation of such a platform to produce welltrained clinicians who simultaneously provide empathetic care and also find joy in their work.
9. Krasner MS, Epstein RM, Beckman H, Suchman AL, Chapman B, Mooney CJ, et al. Association of an educational program in mindful communication with burnout, empathy, and attitudes among primary care physicians. JAMA. 2009 Sep 23;302(12):1284-93.

10. Shapiro SL, Austin JA, Bishop SR, Cordova M. Mindfulness-based stress reduction for health care professionals: results from a randomized trial. Int J. Stress Manag. 2005 May; 12(2):164-76.

11. Mann K, Gordon J, MacLoed A. Reflection and reflective practice in health professions education: a systematic review. Adv in Health Sci Educ. 2009 Oct;14(4):595-621.

12. Klass P. Morality Tales. Harvard Medicine Magazine. 2019 Winter ed. https://hms.harvard.edu/magazine/ethics/morality-tales. Cited March 15, 2019.

13. The Moth. The Moth: True Stories Told Live. Available from: https://themoth.org/about. Cited March 15, 2019.

14. Neumann M, Edelhäuser F, Tauschel D, Fischer M, Wirtz M, Woopen C, et al Empathy decline and its reasons: a systematic review of studies with medical students and residents. Acad Med. 2011 Aug;86(8):996-1009.

15. Clarke L, de Jong J. The value of story in medicine and medical education: a chance to reflect. Journal for Learning Through the Arts. 2012;8(1).

\section{Acknowledgments}

The authors would like to thank the Lamar Soutter Library at the University of Massachusetts Medical School as well as the Organization Medicine student group for their support of Med Moth. The authors would also like to thank Kate Sullivan, a research coordinator in the Department of Family Medicine and Community Health at UMMS for her work in data management to facilitate the survey data's analysis.

\section{Conflict of Interest Statement at Funding}

The Authors have no funding, financial relationships or conflicts of interest to disclose.

\section{Author Contributions}

Conceptualization: MS, SO, HS, ME, JS; Data Curation: MS, SO, JS; Formal Analysis: MS, SO, JS; Investigation: MS, SO, JS; Methodology: MS, SO, HS, ME, JS; Project Administration: MS, SO, HS, ME, JS; Resources: MS, SO, HS, ME, JS; Software: JS; Supervision: MS, SO, HS, ME, JS; Validation: MS, SO; Visualization: MS, SO, HS, ME, JS; Writing - Original Draft Preparation: MS, SO, HS, ME, JS; Writing - Review At Editing: MS, SO, HS, ME, JS.

\section{Cite as}

Silver M, Ohnigian S, Silk H, Ennis M, Savageau J. Med Moth: A Storytelling Platform for Improving Wellness in Medical Education. Int J Med Students. 2021 Oct-Dec; $9(4): 300-3$.

This work is licensed under a Creative Commons Attribution 4.0 International License

ISSN 2076-6327

This journal is published by the University Library System, University of Pittsburgh as part of the Digital Publishing Program and is co-sponsored by the University of Pittsburgh Press. 